\title{
Abducens nerve palsy during pegvisomant therapy in an acromegalic patient
}

\author{
Esra Hatipoglu ${ }^{1}$, Hasan Kepicoglu ${ }^{1}$, Emel Basar ${ }^{2}$, Nurperi Gazioglu ${ }^{3}$, Civan Islak ${ }^{4}$, Sabahattin Saip ${ }^{5}$, \\ Pinar Kadioglu ${ }^{1 \#}$ \\ ${ }^{1}$ Division of Endocrinology and Metabolism, Department of Internal Medicine, Cerrahpasa Faculty of Medicine, Istanbul University, \\ Istanbul, Turkey \\ ${ }^{2}$ Department of Ophthalmology, Cerrahpasa Faculty of Medicine, Istanbul University, Istanbul, Turkey \\ ${ }^{3}$ Department of Neurosurgery, Cerrahpasa Faculty of Medicine, Istanbul University, Istanbul, Turkey \\ ${ }^{4}$ Department of Radiology, Cerrahpasa Faculty of Medicine, Istanbul University, Istanbul, Turkey \\ ${ }^{5}$ Department of Neurology, Cerrahpasa Faculty of Medicine, Istanbul University, Istanbul, Turkey \\ Email: "kadioglup@yahoo.com
}

Received 3 April 2013; revised 3 May 2013; accepted 11 May 2013

Copyright (c) 2013 Esra Hatipoglu et al. This is an open access article distributed under the Creative Commons Attribution License, which permits unrestricted use, distribution, and reproduction in any medium, provided the original work is properly cited.

\begin{abstract}
Pegvisomant is a recent treatment modality of acromegaly, which is most effective in regulating IGF-1 levels. Tumor growth has been reported in $5 \%$ of the acromegaly cases treated with pegvisomant. Herein we report a case of acromegaly resistant to surgical treatment, radiotherapy and medical therapy with a somatostatin analogue and cabergolin. Due to presence of pituitary tumor with cavernous sinus invasion and unremitting disease activity pegvisomant therapy was initiated. She developed left abducens nerve palsy after pegvisomant treatment. The objective of this report is to emphasize the value of close follow-up of the acromely cases under pegvisomant therapy, especially if they have cavernous sinus infiltrating tumor. A 44-yearold woman with acromegaly presented with visual defect and diplopia on left lateral gaze. Her complaint developed 3 years after initiation of pegvisomant therapy. Her neurologic examination was consistent with mild abducens nerve palsy on left side. Other causes for abducens nerve palsy were excluded. Pegvisomant was discontinued upon patient request. Although sella MRI did not reveal a tumor growth, even minimal growth within cavernous sinus can cause cranial nerve involvement. Therefore close and careful follow-up of cavernous sinus infiltrating tumors after pegvisomant therapy is crucial to early recognition of complications.
\end{abstract}

\footnotetext{
*Declaration of Interest: The authors declare that there is no conflict of interest that could be perceived as prejudicing the impartiality of the case reported.

Funding: This case report did not receive any specific grant from any funding agency in the public commercial, or not-for-profit sector.

\#Corresponding author.
}

Keywords: Acromegaly; Pegvisomant; Tumor Growth, Cavernous Sinus; Abduscence Nerve palsy

\section{INTRODUCTION}

Acromegaly is an endocrine disorder characterized by chronic excess of growth hormone (GH) and insulin like growth factor-1 (IGF-1) due to a pituitary adenoma. It has a 3 - 4 cases/million population/year of incidence and is equally seen in both genders [1].

First symptoms of the disease include non-specific complaints like arthralgia, hyperhidrosis and numbness in the hands so the diagnosis is usually delayed and recognised after 40 years of age [1-3]. More prominent findings including enlarged hands and feet and coarse facial features appear later during the course of the disease [14].

Elevated levels of GH concentration after a glucose load and concurrent high serum IGF-I levels confirm the diagnosis of acromegaly. Serum IGF-I concentration, which is interpreted according to the patient's age, is a reliable test for providing a discrimination from normal individuals [5,6].

The main treatment in acromegaly is transsphenoidal surgery. A recent treatment modality is pegvisomant, a pegylated recombinant analog of human GH. Pegvisomant is the most efficient medical treatment in decreasing IGF-1 activity [7]. Herein we report a case with acromegaly who had sixth cranial nerve palsy after inititation of pegvisomant therapy.

\section{CASE REPORT}

A 44-year-old woman presented with progressive head- 


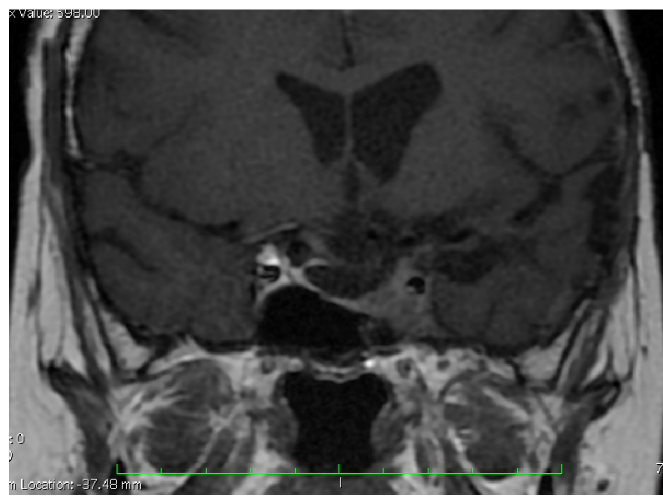

(a)

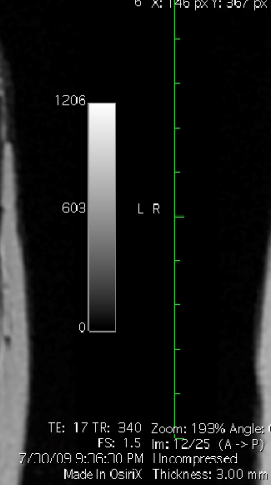

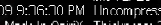

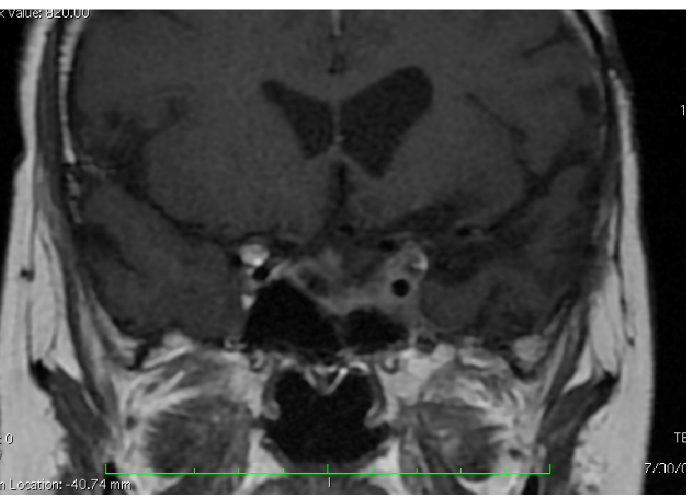

(b)

Figure 1. Coronal MRI with contrast before pegvisomant therapy (A and B).

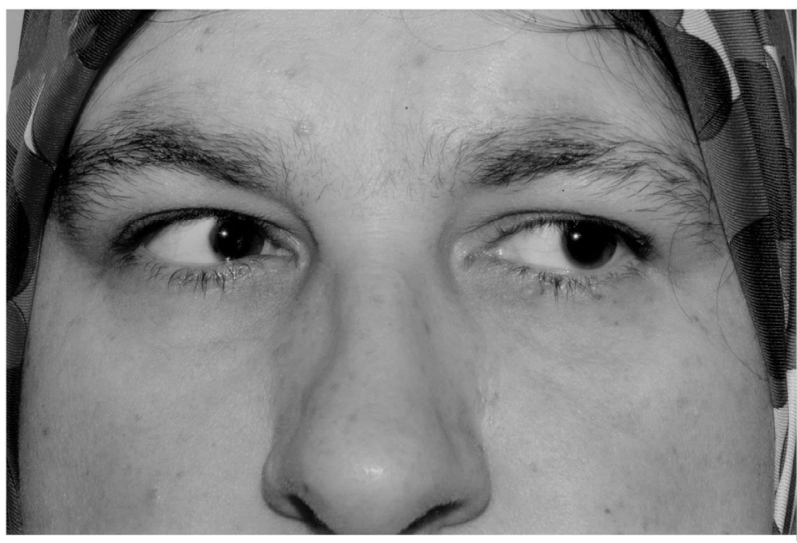

(a)

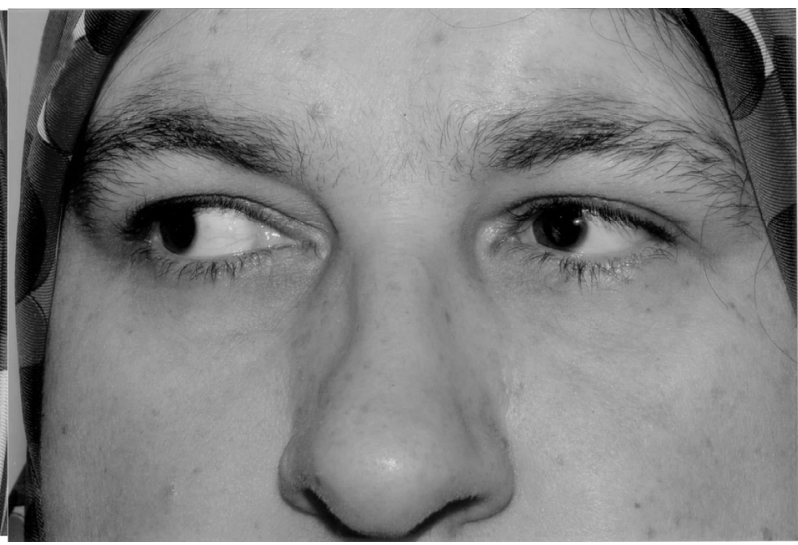

(b)

Figure 2. Partial abducens nerve palsy on left side (A) sclera is not visible on right lateral gaze (B) sclera is visible on left lateral gaze.

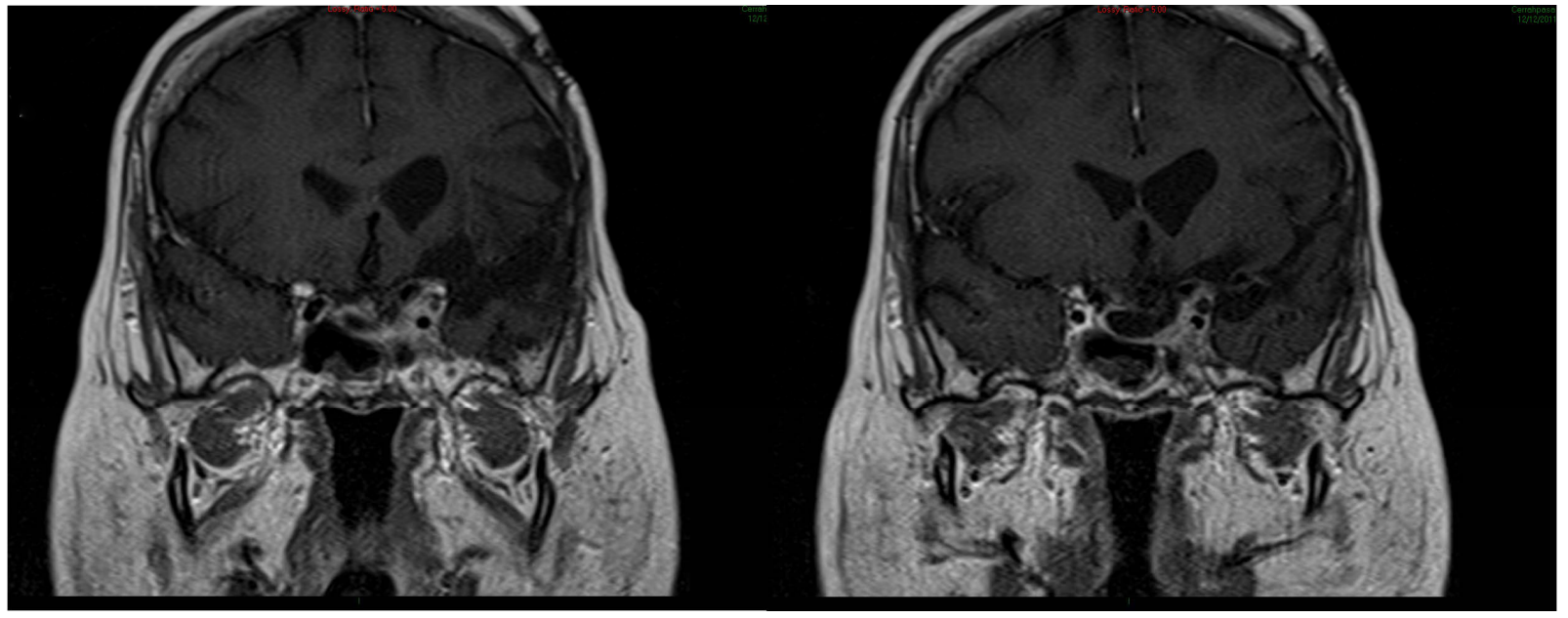

(a)

(b)

Figure 3. Coronal MRI with contrast after pegvisomant therapy—showing caver nous sinus invasion (A and B).

ache and peripheral visual defect with diplopia which were prominent on attempted left lateral gaze. Fifteen years ago she was diagnosed with acromegaly due to 43 $\times 32 \times 24 \mathrm{~mm}$ cavernous sinus infiltrating pituitary adenoma. She had transsphenoidal surgery and operations through craniotomy for two times in consecutive years. 
Pathologic examination revealed a pituitary adenoma with mixed hormone secretion (40\% GH and 20\% prolactin) and 2\% - 4\% Ki-67 index but no p-53 activity. She had conventional RT and gamma knife (GKN) therapy 12 years and 10 years ago, respectively. octreotide analogue was initiated 12 years ago and the dose was titrated up to $40 \mathrm{mg}$ per 28 days. However in the 9 th year of gamma knife therapy GH level was $1.4 \mathrm{ng} / \mathrm{mL}$ and IGF-1 level was 456 ng/mL (N: 101 - 284 ng/mL). Sella MRI showed $11 \mathrm{~mm}$ of residual pituitary adenoma (Figures $1 \mathbf{A}$ and B). Subcutaneous injection of $10 \mathrm{mg}$ pegvisomant per day was initiated and octreotide analogue dose was decreased to $30 \mathrm{mg}$ per 28 days. In the last year of her follow-up pegvisomant dose was changed to 20 mg on alternate days.

Before the pegvisomant therapy she had no complaints about her vision and her visual tests were normal. In the third year of pegvisomant therapy her complaints of headache and peripheral visual loss with diplopia especially on left lateral gaze appeared and progressed over time. Her complete neurologic examination was normal except mild sixth cranial nerve palsy on left side (Figures 2A and B). IGF-1 level was within normal limits according to her age (269 ng/mL, N: 101 - $284 \mathrm{ng} / \mathrm{mL}$ ). Residual tumor did not reveal a prominent difference from previous images on sella MRI comparison (Figures 3A and B). Intracranial hypertension was excluded by lumbar puncture which revealed an opening pressure of $155 \mathrm{~mm}$ $\mathrm{H}_{2} \mathrm{O}$. She had diabetes mellitus for 3 years, HbA1c level was $6.9 \%$ and blood glucose levels were under control with metformin.

Routine laboratory tests did not reveal a specific pathology to point out a secondary cause for the sixth cranial nerve palsy. Detailed and serial eye examinations, including Hess and Word tests with peripheral visual test, were repeated on consecutive weeks and confirmed the presence of sixth cranial nerve palsy on the left with quadranopsic visual field loss comprising left upper temporal and left lower nasal regions. Pegvisomant therapy was discontinued upon patient request. During her follow-up, 2 months after discontinuation of pegvisomant her complaints did not show any improvement.

\section{DISCUSSION}

Pegvisomant therapy is the most recent medical treatment modality of acromegaly. Pegvisomant acts through $\mathrm{GH}$ receptors and does not supress GH levels. Elimination of negative feedback mechanism that control GH secretion may theoretically cause tumor growth. However this has not been based on clear evidence and in literature tumor growth has been reported to be $2.9 \%-5.3 \%$ of the cases $[8,9]$. Adverse effects of pegvisomant therapy include injection-site reactions, liver toxicity, influ- enza-like syndrome, headache, asthenia, diarrhea, arthralgia and hypercholesterolemia [7]. Liver toxicity is usually reversible after decrease or discontinuation of pegvisomant [7]. Pegvisomant is also associated with lipohypertrophy at the injection site or at distant sites [10, 11].

Abducens nerve palsy is associated with dysfunction of sixth cranial nerve. The resultant disturbance in abduction of lateral rectus muscle prevents the eye from turning outward on the involved side. This results in a convergent strabismus of which the primary symptom is diplopia. Conventional RT and GKN are well-known causative factors for cranial nerve palsies. Our patient had RT 12 years ago and GKN 10 years ago. In literature the mean follow-up periods until emergence of cranial nerve palsy after RT/GKN for pituitary adenomas were lower than the period in this case [12-14]. Therefore, RT or GKN were less propable causes for abducens nerve palsy after such a long time. In addition emergence of diplopia after pegvisomant therapy brings questions regarding pegvisomant as the causative agent.

Cavernous sinus infiltration is frequent during the course of acromegaly and when present cranial nerve palsy is usually a consequence of it. Tumor growth secondary to pegvisomant therapy or involvement of cavernous sinus may be possible explanations to the abducens nerve palsy in the presented case. Despite the absence of a difference in comparison of serial MRI images it is possible that pegvisomant have caused a minimal growth of the tumor within the cavernous sinus. Moreover absence of related symptoms prior to initiation of pegvisomant and exclusion of secondary causes have aroused the suspicion of an association with the treatment. On the other hand the exact mechanism underlying this condition is unclear.

To our knowledge this is the first case in the literature reporting development of a cranial nerve palsy during pegvisomant therapy without a certain secondary cause. However the causality is indeterminate and it would be speculative to claim the pegvisomant therapy as the sole liable determinant. During pegvisomant therapy more careful monitorization of tumors with cavernous sinus infiltration and additional reports are necessary to reveal this ambiguity.

\section{ACKNOWLEDGEMENTS}

Informed consent was obtained from the patient.

\section{REFERENCES}

[1] Ben-Shlomo, A. and Melmed, S. (2008) Acromegaly. Endocrinology Metabolism Clinics of North America, 37, 101-122. doi:10.1016/j.ecl.2007.10.002 
[2] Bondanelli, M., Ambrasio, M.R. and Degli Uberti, E.C. (2001) Pathogenesis and prevalence of hypertension in acromegaly. Pituitary, 4, 239-249. doi:10.1023/A:1020798430884

[3] Colao, A., Ferone, D., Marzullo, P. and Lombardi, G. (2004) Systemic complications of acromegaly: Epidemiology, pathogenesis, and management. Endocrine Reviews, 25, 102-150. doi:10.1210/er.2002-0022

[4] Fatti, L.M., Scacchi, M., Pincelli, A.I., Lavezzi, E. and Cavagnini, F. (2001) Prevalence and pathogenesis of sleep apnoea in acromegaly. Pituitary, 4, 259-262. doi:10.1023/A:1020702631793

[5] Clemmons, D.R., Van Wyk, J.J., Ridgway, E.C., Kliman, B., Kjellberg, R.N. and Underwood, L.E. (1979) Evaluation of acromegaly by radio immuno assay of somatomedin-C. The New England Journal of Medicine, 301, 11381142. doi:10.1056/NEJM197911223012102

[6] Stoffel-Wagner, B., Springer, W., Bidlingmaier, F. and Klingmüller, D. (1997) A comparison of different methods for diagnosing acromegaly. Clinical Endocrinology, 46, 531-537. doi:10.1046/j.1365-2265.1997.1430983.x

[7] Van der Lely, A.J., Hutson, R.K., Trainer, P.J., Besser, G.M., Barkan, A.L., Katznelson, L., Klibanski, A., Herman-Bonert, V., Melmed, S., Vance, M.L., Freda, P.U., Stewart, P.M., Friend, K.E., Clemmons, D.R., Johannsson, G., Stavrou, S., Cook, D.M., Phillips, L.S., Strasburger, C.J., Hackett, S., Zib, K.A., Davis, R.J., Scarlett, J.A. and Thorner, M.O. (2001) Long-term treatment of acromegaly with pegvisomant, a growth hormone receptor antagonist. Lancet, 358, 1754-1759. doi:10.1016/S0140-6736(01)06844-1

[8] van der Lely, A.J., Biller, B.M., Brue, T., Buchfelder, M., Ghigo, E., Gomez, R., Hey-Hadavi, J., Lundgren, F., Rajicic, N., Strasburger, C.J., Webb, S.M. and Koltowska-Häggström, M. (2012) Long-term safety of peg- visomant in Patients with acromegaly: Comprehensive review of 1288 subjects in acrostudy. The Journal of Clinical Endocrinology \& Metabolism, 97, 1589-1597. doi:10.1210/jc.2011-2508

[9] Buchfelder, M., Weigel, D., Droste, M., Mann, K., Saller, B., Brübach, K., Stalla, G.K., Bidlingmaier, M., Strasburger, C.J. and Investigators of German Pegvisomant Observational Study (2009) Pituitary tumor size in acromegaly during pegvisomant treatment: Experience from MR re-evaluations of the German pegvisomant observational study. European Journal of Endocrinology, 161, 27-35. doi:10.1530/EJE-08-0910

[10] Bonert, V.S., Kennedy, L., Petersenn, S., Barkan, A., Carmichael, J. and Melmed, S. (2008) Lipodystrophy in patients with acromegaly receiving pegvisomant. Journal of Clinical Endocrinology \& Metabolism, 93, 3515. doi:10.1210/jc.2008-0833

[11] Buyuktas, D., Celik, O., Kantarci, F. and Kadioglu, P. (2010) Lipodystrophy during pegvisomant therapy: A case report and review of the literature. Clinics (Sao Paulo), 65, 931-933. doi:10.1590/S1807-59322010000900018

[12] Petrovich, Z., Yu, C., Giannotta, S.L., Zee, C.S. and Apuzzo, M.L. (2003) Gamma knife radio surgery for pituitary adenoma: Early results. Neurosurgery, 53, 51-61. doi:10.1227/01.NEU.0000068702.00330.47

[13] Vaphiades, M.S., Spencer, S.A., Riley, K., Francis, C., Deitz, L. and Kline, L.B. (2011) Radiation-induced ocular motor cranial nerve palsies in patients with pituitary tumor. Journal of Neuro-Ophthalmology, 31, 210-213. doi:10.1097/WNO.0b013e31820eb7bc

[14] Cifarelli, C.P., Schlesinger, D.J. and Sheehan, J.P. (2012) Cranial nerve dysfunction following gamma knife surgery for pituitary adenomas: Long-term incidence and risk factors. Journal of Neurosurgery, 116, 1304-1310. doi:10.3171/2012.2.JNS111630 